\title{
Minor and major consolidations in inverse DEA: Definition and determination
}

\author{
Gholam R. Amin ${ }^{\mathrm{a}}$, Ali Emrouznejad ${ }^{\mathrm{b}, *}$, Said Gattoufi ${ }^{\mathrm{c}}$ \\ ${ }^{a}$ Faculty of Business, University of New Brunswick at Saint John, NB E2L 4L5, Canada \\ b Operations \& Information Management Group, Aston Business School, Aston University, Birmingham, UK \\ ${ }^{\mathrm{C}}$ Laboratoire SOIE, Institut Supérieur de Gestion de Tunis, Université de Tunis, Tunisia
}

\section{A R T I C L E I N F O}

Article history:

Received 28 December 2015

Received in revised form 23 November 2016

Accepted 24 November 2016

Available online 25 November 2016

\section{Keywords:}

Merger

Major consolidation

Minor consolidation

Efficiency

Inverse Data Envelopment Analysis

(InvDEA)

\begin{abstract}
A B S T R A C T
Many production systems have acquisition and merge operations to increase productivity. This paper proposes a novel method to anticipate whether a merger in a market is generating a major or a minor consolidation, using Inverse data envelopment analysis (InvDEA) model. A merger between two or more decision making units (DMUs) producing a single merged DMU that affects the efficiency frontier, defined by the pre-consolidation market conditions, is called a major consolidation. The corresponding alternative case is called a minor consolidation. A necessary and sufficient condition to distinguish the two types of consolidations is proven and two numerical illustrations in banking and supply chain management are discussed. The crucial importance of anticipating the magnitude of a consolidation in a market is outlined.
\end{abstract}

Crown Copyright @ 2016 Published by Elsevier Ltd. This is an open access article under the CC BY license (http://creativecommons.org/licenses/by/4.0/).

\section{Introduction}

An inverse optimization problem for a given feasible solution of an optimization problem consists of determining the least perturbation in the objective function's coefficients of the optimization problem in order to make the given feasible solution optimal for the perturbed model, as suggested in Ahuja and Orlin (2001). Though it is relatively recent concept, inverse optimization became a popular method to the extend it generated a new research stream in the optimization theory. This new research stream has been continuously enriched by new applications an increasingly large variety of disciplines. Wang, Xu, and Wang (2014), Ruiz, Conejo, and Bertsimas (2013), Chow and Recker (2012), Roch, Canelas, and Herskovits (2012), Pibernik, Zhang, Kerschbaum, and Schröpfer (2011), Terekhov and Zatsiorsky (2011), and Amarchinta, Grandhi, Clauer, Langer, and Stargel (2010) are just few examples of the most recent works. Within this stream, some researchers paid attention to the particular case of inverse linear programming, as exemplified in Zhang and Liu (1996), Huang and Liu (1999), Amin and Emrouznejad (2007a), Zhang and Xu (2010), and Jiang, Xiao, Zhang, and Zhang (2011). The interest in this paper goes to the inverse data envelopment analysis (InvDEA) introduced in

\footnotetext{
* Corresponding author.

E-mail addresses: gamin@unb.ca (G.R. Amin), a.Emrouznejad@aston.ac.uk (A Emrouznejad)
}

Wei, Zhang, and Zhang (2000) and subsequently discussed in Yan, Wei, and Hao (2002), Amin and Emrouznejad (2007b), Lertworasirikul, Charnsethikul, and Fang (2011).

Despite the beauty of the concept of the InvDEA, the dedicated literature remained limited over years. Lertworasirikul et al. (2011) and Ghiyasi (2015) proposed an inverse BCC model for a resource allocation problem. Many production systems have acquisition and merge operations to increase productivity (Liu \& Li, 2009). Recently, Gattoufi, Amin, and Emrouznejad (2014) extended the concept of InvDEA and suggested an application in banking merger. Their suggested approach determines the aggregated amount of resources among those inherited from merging banks by the merged bank in order to achieve a predefined efficiency target. More recently, Amin and Al-Muharrami (2016) introduced new InvDEA method for mergers with negative data.

Though the DEA literature was continuously enriched with new concepts, as reported in Gattoufi, Oral, Kumar, and Reisman (2004), Emrouznejad, Parker, and Tavares (2008), Emrouznejad and De Witte (2010), and Liu, Lu, Lu, and Lin (2013) many of those interesting developments like InvDEA remained purely theoretical without any real world application. This paper contributes to filling this gap by giving real world dimension for InvDEA through the introduction of the new concepts of major and minor consolidations with an illustration from the banking industry.

A minor consolidation corresponds to the case where a merger between two, or more, decision making units (DMUs) has no effect 
on the pre-consolidation efficiency frontier. If any effect occurs, the corresponding consolidation is defined as major. This paper develops an InvDEA method to anticipate the type of consolidation generated by a merger, a major or a minor, for the decision makers to plan the appropriate actions required by the post-consolidation market conditions.

Identifying major consolidations in a market will help regulating authorities, like anti-trust departments in USA and many countries, identifying those consolidations that potentially threaten the competitiveness in the market and hence thoroughly analyze the case before its approbation. On the other hand, consolidations identified as minor can be approved in a quicker way.

Moreover, business intelligence units in a firm may use what we propose to identify the possible threats in their business environment. One way of doing it is to use the scenario approach to identify, among all possible consolidations, those that are major in the market and hence represents the potential threat for the competitiveness of the firm. A major consolidation may in fact alter the pre-consolidation efficiency frontier, and hence change the level of competitiveness in the market, to an extent that offsets any internal efficiency improvement. The proposed approach helps determining the required additional effort to offset the "technology change" generated by the new consolidation(s) in the postconsolidation market condition.

Finally, the new InvDEA based approach can help firm strategy decision makers identifying their targeted partner(s) in case a future consolidation is considered by the firm as part of their strategy.

Nevertheless, the new approach introduced in this paper does not allow for cross-market or cross-sector analysis. Many consolidations are in fact of these types. This limitation is due to the basic assumptions required for the application of the DEA, and consequently the InvDEA based method proposed in this paper. Additional works are needed to generalize what is proposed in this paper to such cases.

In the rest of this paper, Section 2 illustrates the fundamental concepts called in the paper, namely minor and major consolidations, using InvDEA. Section 3 defines minor and major consolidations in general form and suggest necessary and sufficient conditions to identify the type of merger using appropriate InvDEA models. Two applications in banking and supply chain industries are used to show the usefulness of the proposed method in Section 4. Finally, concluding remarks and directions for future researches are provided in Section 5.

\section{Basic concept: Illustration}

Many examples of measuring efficiency and productivity of firm and production lines using standard DEA can be found in the literature. However, markets nowadays go through continuous restructuring in all industries, which will require a new form of DEA to measure the efficiency and productivity after restructuring. Among the forms that take these endless mutations, the most popular are mergers and acquisitions that happen in any industry for those firms to consolidate their activities in order to improve their performance. A simple case of a market formed by five banks to illustrate the new concepts this paper is introducing. Two of the banks, or DMUs, are going into merger to consolidate their activities by creating a new banking unit.

As shown in Table 1, each bank uses labor as single input in order to produce loans as single output. Nevertheless, this illustration is not limited to the banking sector and any other industry can be used for the same purpose. The corresponding Production Possibility Set (PPS) for the five banks is shown in Fig. 1. Assume that the two banks that are going into merger are D and E in Fig. 1.
Table 1

Numerical example.

\begin{tabular}{lll}
\hline DMUs & Labor & Loan \\
\hline A & 2.00 & 2.50 \\
B & 2.50 & 3.25 \\
C & 5.00 & 4.25 \\
D & 2.25 & 2.25 \\
E & 3.50 & 1.50 \\
\hline
\end{tabular}

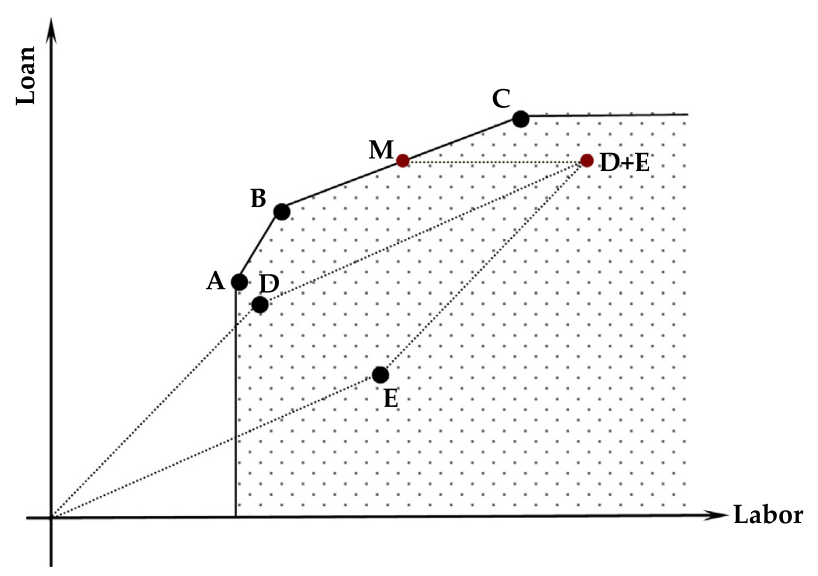

Fig. 1. Production Possibility Set for five banks.

In practice, such consolidation is usually accompanied by the definition of a target in terms of performance. Assume that a targeted level of efficiency, or inefficiency, is predefined for the merged bank, technical efficiency being a reliable indicator of the performance.

The illustration in this section is made under the input orientation assumption as defined in Gattoufi et al. (2014). This assumption implies that, keeping its loans at the level of the sum of loans of merging banks, the merged bank realizes the targeted efficiency with a minimum level of labor. However, the same illustration can be conducted under the output orientation assumption.

Consider the virtual DMU D + E shown in Fig. 1, with its input and output being the sum of those of $\mathrm{D}$ and $\mathrm{E}$. Let $\mathrm{M}$ and $\bar{\theta}$ denote respectively the merged bank and its efficiency score target. In line with the assumption that mergers are meant to improve the performance of merging entities, the following inequality applies

$\max \left\{\theta_{D}^{*}, \theta_{E}^{*}, \theta_{D+E}^{*}\right\} \leqslant \bar{\theta} \leqslant 1$

where $\theta_{D}^{*}, \theta_{E}^{*}$ and $\theta_{D+E}^{*}$ are respectively the efficiency scores of D, E, and $\mathrm{D}+\mathrm{E}$.

However, this may not be valid in some real cases of failing mergers. Similar situations are excluded from the analysis in this paper.

Moreover, the variable return to scale (VRS) assumption, as defined in Banker, Charnes, and Cooper (1984), is assumed in this paper. This is in line with fact that mergers are meant to create synergy, and hence the proportionality assumption required by constant return to scale (CRS), as defined in Charnes, Cooper, and Rhodes (1978), is not valid.

The efficiency scores, obtained by solving the input oriented VRS DEA model with data from Table 1 , for D, E, and D + E are

$\theta_{D}^{*}=0.889, \quad \theta_{E}^{*}=0.571, \quad \theta_{D+E}^{*}=0.652$

Hence, the efficiency score target for the merged bank M can be any value $\bar{\theta}$ within the range $0.889 \leqslant \bar{\theta} \leqslant 1$.

The objective in InvDEA model, as suggested in Gattoufi et al. (2014), is to determine the minimum level of labor required for 
the merged bank to achieve its predetermined efficiency score target. The corresponding input oriented VRS InvDEA model is

$$
\begin{array}{ll}
\min & \alpha_{D}+\alpha_{E} \\
\text { s.t. } & \\
& 2 \lambda_{A}+2.5 \lambda_{B}+5 \lambda_{C}+\left(\alpha_{D}+\alpha_{E}\right) \lambda_{M}-\left(\alpha_{D}+\alpha_{E}\right) \bar{\theta} \leqslant 0 \\
& 2.5 \lambda_{A}+3.25 \lambda_{B}+4.25 \lambda_{C}+3.75 \lambda_{M} \geqslant 3.75 \\
& \lambda_{A}+\lambda_{B}+\lambda_{C}+\lambda_{M}=1 \\
& 0 \leqslant \alpha_{D} \leqslant 2.25, \quad 0 \leqslant \alpha_{E} \leqslant 3.5 \\
& \lambda_{A} \geqslant 0, \quad \lambda_{B} \geqslant 0, \quad \lambda_{C} \geqslant 0, \quad \lambda_{M} \geqslant 0
\end{array}
$$

where $\alpha_{D}$ and $\alpha_{E}$ are the levels of labor left after reduction of the levels inherited by the merged bank $M$ from the merging banks $D$ and E, respectively. This nonlinear programming model can be linearized to the following linear programming model

$$
\begin{array}{ll}
\min & \alpha_{D}+\alpha_{E} \\
\text { s.t. } & \\
& 2 \lambda_{A}+2.5 \lambda_{B}+5 \lambda_{C}-\left(\alpha_{D}+\alpha_{E}\right) \bar{\theta} \leqslant 0 \\
& 2.5 \lambda_{A}+3.25 \lambda_{B}+4.25 \lambda_{C} \geqslant 3.75 \\
& \lambda_{A}+\lambda_{B}+\lambda_{C}=1 \\
& 0 \leqslant \alpha_{D} \leqslant 2.25, \quad 0 \leqslant \alpha_{E} \leqslant 3.5 \\
& \lambda_{A} \geqslant 0, \quad \lambda_{B} \geqslant 0, \quad \lambda_{C} \geqslant 0
\end{array}
$$

This trivial simplification, obtained by assuming $\lambda_{M}=0$, will be discussed in the next section.

Assume that the target for the merged bank $\mathrm{M}$ is to be fully efficient, equivalently $\bar{\theta}=1$. The above model will have then the following optimal solution

$\left(\lambda_{A}^{*}, \lambda_{B}^{*}, \lambda_{C}^{*}, \alpha_{D}^{*}, \alpha_{E}^{*}\right)=(0,0.5,0.5,2.25,1.5)$

Hence, the labor level for the merged bank will be $2.25+1.5=3.75$, obtained by keeping the inherited level from $D$ unchanged and reducing the inherited level from $\mathrm{E}$ by $x_{E}-\alpha_{E}^{*}=3.5-1.5=2$ units.

It is worth mentioning that in the above consolidation case, shown in Fig. 1, the merger did not affect the efficiency frontier. The virtual DMU, D + E in Fig. 1, is in fact a feasible point in the current PPS. The limit case, shown in

Fig. 2, represents the situation where the virtual bank $\mathrm{D}+\mathrm{E}$ is on the efficiency frontier. Even in this case, corresponding to $\bar{\theta}=\theta_{D+E}^{*}=1$, the efficiency frontier is not affected.

For the two cases depicted in Figs. 1 and 2, where the merger does not affect the current efficiency frontier, the authors suggest the new appellation of minor consolidation. On the other hand, if the merger affects the efficiency frontier, it is given the appellation of major consolidation. This former case is illustrated in Fig. 3.

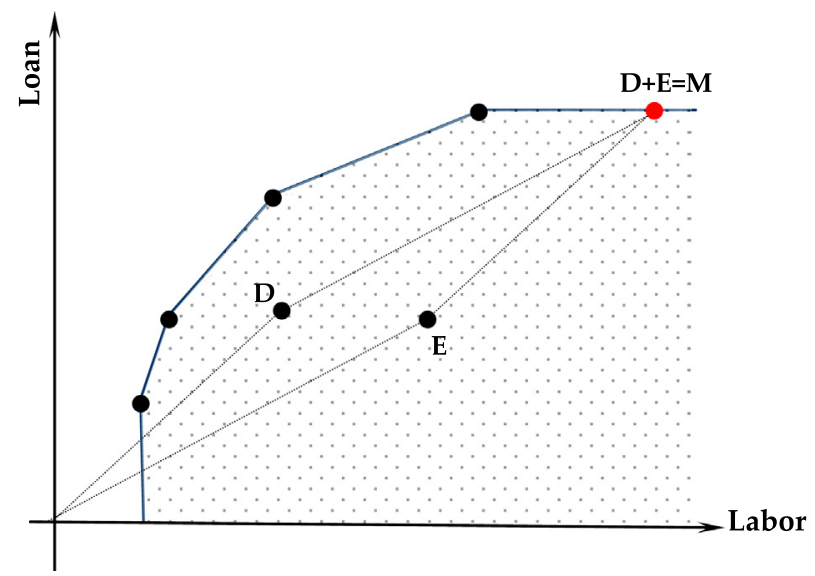

Fig. 2. A merger not affecting the current efficiency frontier.

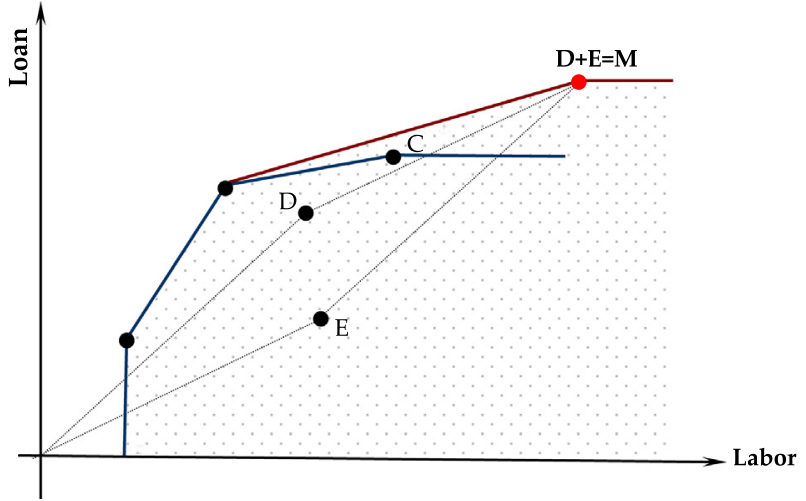

Fig. 3. A merger affecting the current efficiency frontier.

Identifying the type of consolidation, whether a minor or major, has a critical importance for all DMUs competing in the market witnessing the consolidation. It defines the new market conditions in the way it indicates whether their current relative efficiency level will be affected in the post-merger market. The occurrence of a major consolidation changes the competition level in the market to the extent it alters the benchmarking process as indicated by the change in the efficiency frontier.

Consider the major consolidation, shown in Fig. 4, where the merged bank $\mathrm{M}$ inherited the inputs and outputs of $\mathrm{D}$ and $\mathrm{C}$.

This consolidation modified the efficiency frontier, and hence worsened the efficiency score of bank $E$ which will have more challenging market conditions. For instance, the output oriented efficiency score of bank E decreased from 0.42 in the preconsolidation market to 0.38 in the post-consolidation market. This decrease represents roughly an $8 \%$ efficiency loss.

The following section defines the general form of minor and major consolidations and suggests a necessary and sufficient condition distinguishing between the two types using InvDEA.

\section{Minor and major consolidations}

For simplicity and without loss of generality, this paper considers the case of a consolidation between two DMUs operating in the same market, both merging units disappearing to generate a new merged entity. Nevertheless, the analysis conducted in this paper can be used for the case of more than two merging DMUs.

Suppose that we have $n$ DMUs where the $j$ th unit $(j=1, \ldots, n)$ uses $m$ resources (or inputs) $x_{i j}(i=1, \ldots, m)$ and produces $s$ prod-

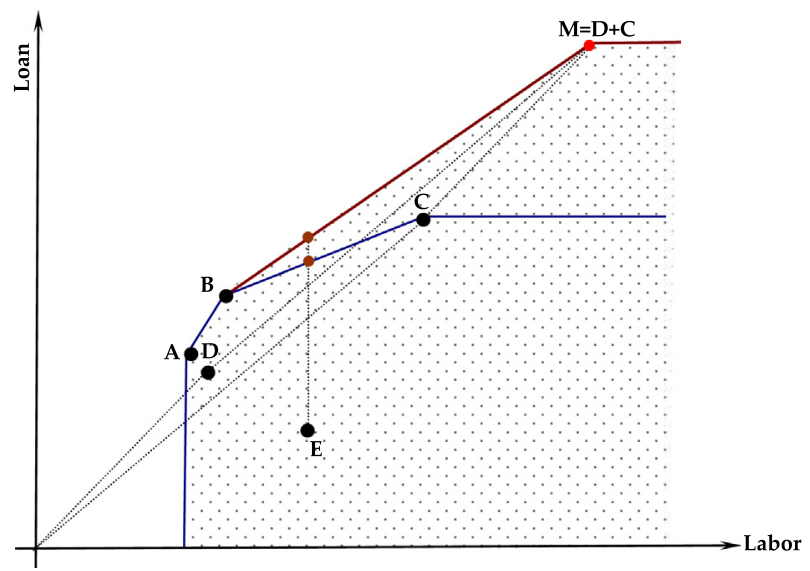

Fig. 4. Impact of a major consolidation on the inherited resources. 
ucts (or outputs) $y_{r j}(r=1, \ldots, s)$. Assume that DMUs $k$ and $l$ are consolidating their activities. Let's $M$ denotes the merged entity generated by the consolidation and also $\mathrm{T}$ indicates the set of indices of all DMUs except $k$ and $l$. For this consolidation Gattoufi et al. (2014) proposed the following input oriented InvDEA model.

$$
\begin{array}{ll}
\min & \sum_{i=1}^{m}\left(\alpha_{i k}+\alpha_{i l}\right) \\
\text { s.t. } & \\
& \sum_{j \in T} x_{i j} \lambda_{j}+\left(\alpha_{i k}+\alpha_{i l}\right) \lambda_{M}-\left(\alpha_{i k}+\alpha_{i l}\right) \bar{\theta} \leqslant 0 \quad i=1, \ldots, m \\
& \sum_{j \in T} y_{r j} \lambda_{j}+\left(y_{r k}+y_{r l}\right) \lambda_{M} \geqslant\left(y_{r k}+y_{r l}\right) \quad r=1, \ldots, s \\
& \sum_{j \in T} \lambda_{j}+\lambda_{M}=1 \\
& 0 \leqslant \alpha_{i k} \leqslant x_{i k} \quad i=1, \ldots, m \\
& 0 \leqslant \alpha_{i l} \leqslant x_{i l} \quad i=1, \ldots, m \\
& \lambda_{j} \geqslant 0 \quad \forall j \in T, \quad \lambda_{M} \geqslant 0
\end{array}
$$

where $\bar{\theta}$ is a predetermined efficiency target for the merged entity $M$. Note that the above InvDEA model is a nonlinear programming (NLP) problem. In what follows, the paper establishes a direct connection between the linearization of the NLP model (1) and newly introduced concepts defined hereafter.

Definition (Major and minor consolidation). A merger that affects the pre-consolidation efficiency frontier is called a major consolidation, otherwise the merger is called a minor consolidation.

The following theorem gives a necessary and sufficient condition to determine whether a merger is a minor or a major consolidation.

Theorem 1. The merger between two DMUs $k$ and $l$ is a minor consolidation if and only if the following model is feasible. Otherwise, it is a major consolidation.

$$
\begin{array}{ll}
\min & \sum_{i=1}^{m}\left(\alpha_{i k}+\alpha_{i l}\right) \\
\text { s.t. } & \sum_{j \in T} x_{i j} \lambda_{j}-\left(\alpha_{i k}+\alpha_{i l}\right) \bar{\theta} \leqslant 0 \quad i=1, \ldots, m \\
& \sum_{j \in T} y_{r j} \lambda_{j} \geqslant\left(y_{r k}+y_{r l}\right) \quad r=1, \ldots, s \\
& \sum_{j \in T} \lambda_{j}=1 \\
& 0 \leqslant \alpha_{i k} \leqslant x_{i k} \quad i=1, \ldots, m \\
& 0 \leqslant \alpha_{i l} \leqslant x_{i l} \quad i=1, \ldots, m \\
& \lambda_{j} \geqslant 0 \quad \forall j \in T
\end{array}
$$

Proof. To show the sufficient condition, assume that model (2) is feasible. Clearly, model (2) is obtained from model (1) by relaxing the nonlinear terms $\left(\alpha_{i k}+\alpha_{i l}\right) \lambda_{M}$, for each $i=1, \ldots, m$. More precisely, model (2) is the linearized form of model (1) by taking $\lambda_{M}=0$. It can be easily shown that model (2) is feasible if and only if the virtual $\mathrm{DMU}_{k+l}=\left(\boldsymbol{x}_{k}+\boldsymbol{x}_{l}, \boldsymbol{y}_{k}+\boldsymbol{y}_{l}\right)$ is in the pre-consolidation PPS, as an interior point or on the efficiency frontier. Therefore, taking into account the feasibility of model (2) concludes that the virtual $\mathrm{DMU}_{k+l}$ can be presented in terms of the DMUs indexed in $\mathrm{T}$ and vice versa. This completes the proof.

Theorem 1 reveals the relation between the type of a consolidation and the feasibility of the relaxed InvDEA model (2). According to Theorem 1 the merger between DMUs $k$ and $l$ is a major consolidation if and only if the relaxed InvDEA (2) is infeasible. In this case the virtual $\mathrm{DMU}_{k+l}$ will be outside the preconsolidation PPS, and therefore the efficiency frontier will be changed. Also, the merged entity $\mathrm{M}$ is the virtual $\mathrm{DMU}_{k+l}$ itself without the need of inputs reduction. As a result, the performance of all DMUs indexed in T should be reassessed. Consequently, the relaxed InvDEA model (2) is a base to distinguish whether the merger changes the frontier or not regardless of the given DMUs $k$ and $l$ are efficient or inefficient.

For an output orientation Gattoufi et al. (2014) proposed the following InvDEA model.

$$
\begin{array}{ll}
\max & \sum_{r=1}^{s} \beta_{r} \\
\text { s.t. } & \\
& \sum_{j \in T} x_{i j} \lambda_{j}+\left(x_{i k}+x_{i l}\right) \lambda_{M} \leqslant\left(x_{i k}+x_{i l}\right) \quad i=1, \ldots, m \\
& \sum_{j \in T} y_{r j} \lambda_{j}+\left(y_{r k}+y_{r l}+\beta_{r}\right) \lambda_{M}-\left(y_{r k}+y_{r l}+\beta_{r}\right) \bar{h} \geqslant 0 \quad r=1, \ldots, s \\
& \sum_{j \in T} \lambda_{j}+\lambda_{M}=1 \\
& \beta_{r} \geqslant 0 \quad r=1, \ldots, s \\
& \lambda_{j} \geqslant 0 \quad \forall j \in T, \quad \lambda_{M} \geqslant 0
\end{array}
$$

Similarly, mergers can be identified as minor or major consolidations using the InvDEA modeling, model (3), under the output orientation assumption, as illustrated in Fig. 5. As it is shown in the figure, the efficient unit $k$ and the inefficient unit $l$ merged into $\mathrm{M}$ and the corresponding virtual $\mathrm{DMU}_{k+l}$ is inside the PPS.

Theorem 2. The merger between two DMUs $k$ and $l$ is a minor consolidation if and only if the following model is feasible. Otherwise, it is a major consolidation.

$$
\begin{array}{ll}
\max & \sum_{r=1}^{s} \beta_{r} \\
\text { s.t. } & \\
& \sum_{j \in T} x_{i j} \lambda_{j} \leqslant\left(x_{i k}+x_{i l}\right) \quad i=1, \ldots, m \\
& \sum_{j \in T} y_{r j} \lambda_{j}-\left(y_{r k}+y_{r l}+\beta_{r}\right) \bar{h} \geqslant 0 \quad r=1, \ldots, s \\
& \sum_{j \in T} \lambda_{j}=1 \\
& \beta_{r} \geqslant 0 \quad r=1, \ldots, s, \quad \lambda_{j} \geqslant 0 \forall j \in T
\end{array}
$$

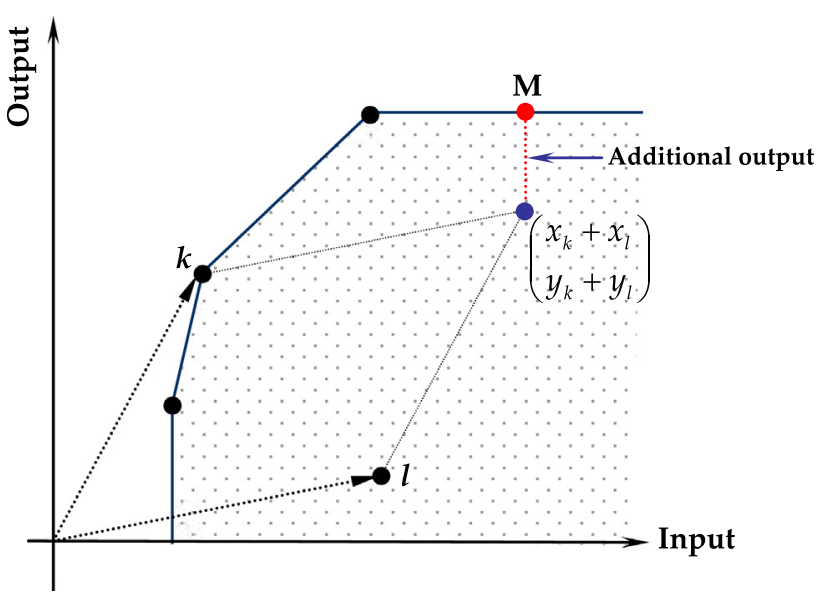

Fig. 5. A minor consolidation under output orientation assumption. 
where $\bar{h}$ is the predefined efficiency target for the merged entity.

Proof. The proof is straightforward. $\square$

\section{Two applications}

\subsection{Mergers in banking}

The banking sector is chosen to illustrate the proposed method in order to show its usefulness and relevance. The dataset used in Gattoufi et al. (2014) is reconsidered in this section, to illustrate the concepts newly introduced in the previous sections of this paper. The dataset consists of 42 commercial banks, assumed to be competing in the same market, using two inputs to produce two outputs. The two inputs are interest expenses and noninterest expenses. Interest expenses covers expenses for deposits and other borrowed funds whilst non-interest expenses stand for the costs of converting deposits into loans, including service charges, commissions, expenses of general management affairs, salaries, and other expenses. In addition, the two outputs are interest income and non-interest income. Interest income includes interest on loans, and income from government securities whilst noninterest income is the service charges on loans and transactions, commissions, and other operating income. Appendix A shows the 42 banks included in the sample and their corresponding VRS efficiency scores obtained from BCC model. We apply our proposed InvDEA method to identify major and minor consolidations in the market represented by the set of commercial banks considered. Assume that two banks, $k$ and $l$, consider going into consolidation through merger. Table 2 shows the results of several mergers scenarios.

The first column in Table 2 lists the merger scenarios considered. The second column provides the nature of the corresponding input oriented InvDEA model (2), where the feasibility of the model is reported. The type of merger resulting from each consolidation scenario is identified in the third column. In case of minor consolidation, the corresponding input oriented VRS efficiency score, $\theta_{k+l}^{*}$, of the virtual bank $\mathrm{B}_{k+l}$ is shown in the last column. Table 2 indicates that each of the first three merger scenarios leads to a major consolidation, while each of the last two produces a minor consolidation. For instance, consider the fourth merger scenario suggested in Table 2, where the merging banks are $k=2$ and $l=3$. The corresponding InvDEA model (2) is feasible and hence the merger is a minor consolidation. In addition, the VRS efficiency score of $\mathrm{DMU}_{2+3}$ shows a lower bound $\theta_{2+3}^{*}=0.68$ for the efficiency target of the merged bank $\mathrm{M}$, or equivalently $0.68 \leqslant \bar{\theta} \leqslant 1$. Assume that the merged bank $M$ sets $\bar{\theta}=1$ as its efficiency target. The corresponding InvDEA model (2) can be used to determine the inputs reductions required for each merging bank in order to realize the targeted efficiency $\bar{\theta}=1$. We have

Table 2

Nature of suggested merger scenarios under input orientation.

\begin{tabular}{llll}
\hline Merging banks & InvDEA model (2) & Type of consolidation & $\theta_{k+l}^{*}$ \\
\hline$k=1, l=2$ & Infeasible & Major & - \\
$k=1, l=4$ & Infeasible & Major & - \\
$k=1, l=6$ & Infeasible & Major & - \\
$k=1, l=3$ & Feasible & Minor & 0.680 \\
$k=17, l=18$ & Feasible & Minor & 0.857 \\
\hline
\end{tabular}

$\min \alpha_{12}+\alpha_{13}+\alpha_{22}+\alpha_{23}$

s.t.

$$
\begin{aligned}
& 39560.796 \lambda_{1}+47100.68 \lambda_{4}+\cdots+6500.83 \lambda_{42} \\
& -\left(\alpha_{12}+\alpha_{13}\right) \times 1 \leqslant 0 \\
& 18940.426 \lambda_{1}+39960.259 \lambda_{4}+\cdots+3070.959 \lambda_{42} \\
& \quad-\left(\alpha_{22}+\alpha_{23}\right) \times 1 \leqslant 0 \\
& 90010.004 \lambda_{1}+12920.337 \lambda_{4}+\cdots+12650.646 \lambda_{42} \\
& \geqslant 9740.854+4790.8 \\
& 87010.497 \lambda_{1}+60600.768 \lambda_{4}+\cdots+4410.359 \lambda_{42} \\
& \geqslant 5970.726+2520.2 \\
& \lambda_{1}+\lambda_{4}+\cdots+\lambda_{42}=1 \\
& 0 \leqslant \alpha_{12} \leqslant 4810.239, \quad 0 \leqslant \alpha_{13} \leqslant 3050.2 \\
& 0 \leqslant \alpha_{22} \leqslant 3190.976, \quad 0 \leqslant \alpha_{23} \leqslant 1380.6 \\
& \lambda_{j} \geqslant 0 \quad \forall j \in T=\{1,4,5, \ldots, 42\}
\end{aligned}
$$

An optimal solution for the above InvDEA model is as follows

$$
\begin{aligned}
& \lambda_{31}^{*}=0.9713, \quad \lambda_{39}^{*}=0.0287, \quad \lambda_{j}^{*}=0 \quad \forall j \neq 31,39 \\
& \alpha_{12}^{*}=3710.2691, \quad \alpha_{13}^{*}=0, \quad \alpha_{22}^{*}=3190.9765, \\
& \alpha_{23}^{*}=1080.2647
\end{aligned}
$$

This means that the interest expenses level for the merged bank $M$ will be $371.2691+0=371.2691$, obtained by reducing the level of interest expenses inherited from B02 by 109.9697 $(=481.2388026-371.2691)$, and eliminating the whole amount of interest expenses inherited from B03.

Similarly, the non-interest expenses level for the merged bank $\mathrm{M}$ will be 428.2412 (= $319.9765+108.2647)$, obtained by keeping the full level of non-interest expenses inherited from $\mathrm{B}_{02}$ and reducing that inherited from $\mathrm{B}_{03}$ by 30.3353 (=138.6 - 108.2647).

Minor and major consolidations can be identified through an output oriented analysis using VRS InvDEA model (4). For this case Gattoufi et al. (2014) assumed that the level of inputs for the merged bank $M$ is kept at the aggregated level of sum of those inherited from merging banks. As for the level of outputs for the merged bank $M$, the objective is to determine the incremental values to be added to the aggregated levels inherited from merging banks, in order to realize its predefined efficiency target. Table 3 provides details about three consolidation scenarios.

The last column of Table 3 provides the output oriented efficiency score, $h_{k+l}^{*}$, of the virtual bank $\mathrm{B}_{k+l}$. For a given output oriented efficiency target $\bar{h}$, satisfying $1 \leqslant \bar{h} \leqslant \min \left\{h_{k}^{*}, h_{l}^{*}, h_{k+l}^{*}\right\}$, the corresponding output oriented VRS InvDEA model (4) can be used to determine how much additional interest and non-interest incomes should be produced for the merged bank to realize the predefined output oriented efficiency target.

Consider the first merger scenario suggested in the first row of Table 3. Assume that the output oriented efficiency target is set as $\bar{h}=1.01$. The corresponding output oriented InvDEA model (4) becomes.

Table 3

Nature of suggested merger scenarios under output orientation.

\begin{tabular}{llll}
\hline Merging banks & InvDEA model (4) & Type of consolidation & $h_{k+l}^{*}$ \\
\hline$k=1, l=2$ & Feasible & Minor & 1.0161 \\
$k=12, l=3$ & Feasible & Minor & 1.5654 \\
$k=1, l=4$ & Infeasible & Major & - \\
\hline
\end{tabular}




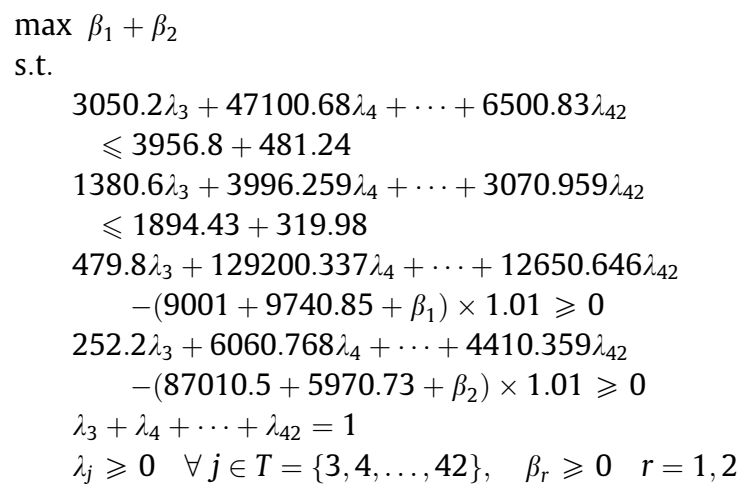

An optimal solution of the above model suggests that the additional outputs are

$\beta_{1}^{*}=120.59, \quad \beta_{2}^{*}=28.24$

This means that the merged bank $M$ can be almost $99 \%\left(\frac{1}{1.01} \cong 0.99\right)$ efficient if it can incrementally produce 120.59 extra units of interest income and 28.24 extra units of non-interest income, on top of the production levels inherited from the merging banks $B_{01}$ and $B_{02}$.

On the other hand, the third consolidation scenario suggested in Table 3 leads to a major consolidation between the merging banks $\mathrm{B}_{01}$ and $\mathrm{B}_{04}$, since the corresponding output oriented InvDEA model (4) is infeasible. In this case, the merged bank $M$ and the virtual bank $\mathrm{B}_{1+4}$ are identical. Hence, the production level will be the exact aggregated level of outputs inherited from the merging banks $\mathrm{B}_{01}$ and $\mathrm{B}_{04}$.

\subsection{Mergers in supply chain industry}

In this section the minor and major consolidation methodology proposed in paper is used to an application in the logistic and supply chain industry. It would be institutive noting that implementing the minor and major consolidations in the logistics and supply chain industry where economies of scale and operational diversity can be immediately relevant in the consideration of a model under the VRS assumption would be more beneficial. We use the data related to ten distributers in the supply chain case study introduced in Mirhedayatian, Azadi, and Farzipoor Saen (2014). Their supply chain application has four divisions consisting of suppliers in the first, producers in the second, distributers in the third and customers in the last division. To be consistent with our modeling, we discuss the possibility of occurring the minor and major consolidations for the distributers in the supply chain application. There are ten distributers each with one input and two outputs as shown in Mirhedayatian et al. (2014). The input is the staff cost (in \$1000) and the two outputs are services and on-time delivery to customers. The dataset for the ten distributers and their VRS efficiency scores are given in Appendix B. For illustration purpose, we consider two merger scenarios. Let us assume the first merger scenario between two inefficient distributers in the Appendix B, $k=$ Damdaran and $l=$ Pegah. Assume that the merged distributer sets $\bar{\theta}=1$ as its efficiency target. The following InvDEA model can be used to identify the type of consolidation.

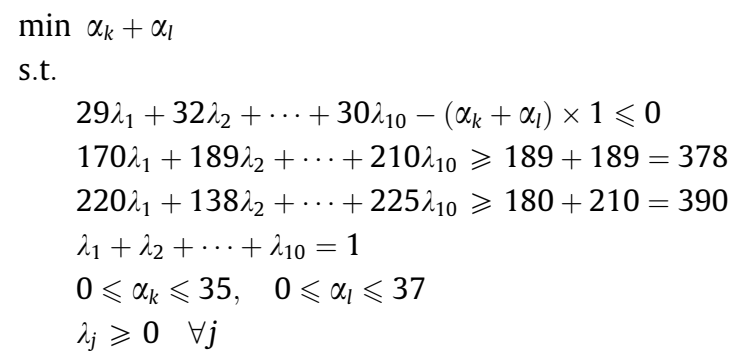

The above InvDEA model is infeasible and therefore according to Theorem 1 the corresponding merger between the two distributors $k=$ Damdaran and $l=$ Pegah would be a major consolidation.

As the second merger scenario, we consider two distributers $k=$ Behnoush and $l=$ Varna. The InvDEA model (2) related to this merger is also infeasible and therefore it would be a major consolidation in the market that might not be likely to happen by the authorities and policy makers. There is no minor consolidation scenario for this application due to good performance of the distributers.

The InvDEA method suggested in this paper can be easily extended to consider more than two merging DMUs producing a single merged DMU without any limitation. The case of multiple merging DMUs producing multiple merged DMUs represents a new direction for future research. So far, a new InvDEA based approach to identify the type of consolidation resulting from the merger of two merging DMUs producing a single merged DMU was introduced. To the best knowledge of the authors, no alternative method to anticipate whether a future consolidation will be or not deeply affecting the competitiveness in the market, and hence be a major consolidation, was suggested in the literature.

It should be noted that the proposed methodology in this paper is based on the inverse optimization. The original and the base model is the standard DEA model which is a deterministic model and consequently the corresponding inverse DEA model would be a deterministic linear programming model. This assumption in the modeling is a limitation to the proposed methodology since a deterministic model always suffers from the drawbacks of uncertainties. As a further research, this methodology can be extended if the stochastic DEA model is considered as the base optimization model.

\section{Concluding remarks and direction for future studies}

As a matter of fact, and unlike other inverse optimization researches, there is a gap between theoretical developments and real world application of inverse data envelopment analysis (InvDEA). This paper introduced a method that puts InvDEA in action in order to anticipate the extent to which a preconsolidation is affected by a merger in the market. A merger is said to be a major consolidation if it affects the efficiency frontier defined by the pre-consolidation market conditions. If postconsolidation efficiency frontier is identical to that of preconsolidation, the merger is described as a minor consolidation. To illustrate the proposed InvDEA method, two applications in banking and supply chain industries are discussed. Identifying major consolidations in a market will help regulating and antitrust authorities identifying those consolidations that potentially threaten the competitiveness in the market and hence thoroughly analyze those cases before any approbation. Moreover, business intelligence units in a firm may use what we propose to identify the possible threats in their business environment. One way of doing it is to use the scenario approach to identify, among all possible consolidations, those that are major in the market and hence represents the potential threat for the competitiveness of the firm. Finally, what we propose can help decision makers identifying their target in case a consolidation is considered by the firm. Nevertheless, the proposed method in this paper has the limitation of not coping with cross-market or cross-sector consolidations. This is due to the basic assumption required for the application of the DEA and hence InvDEA proposed in this paper. Additional works are needed to generalize what is proposed in this paper to such cases.

\section{Acknowledgement}

The authors would like to thank Professor Mohamed I Dessouky, the editor of Computer and Industrial Engineering, and anonymous 
reviewers for their insightful and constructive comments and suggestions, as results the paper has been improved.

\section{Appendix A. GCC banks data and efficiency scores}

\begin{tabular}{|c|c|c|c|c|c|}
\hline Bank & $\begin{array}{l}\text { Interest } \\
\text { expenses }\end{array}$ & $\begin{array}{l}\text { Non- } \\
\text { interest } \\
\text { expenses }\end{array}$ & $\begin{array}{l}\text { Interest } \\
\text { incomes }\end{array}$ & $\begin{array}{l}\text { Non- } \\
\text { interest } \\
\text { incomes }\end{array}$ & $\begin{array}{l}\text { Technical } \\
\text { efficiency } \\
\text { scores } \\
\text { under } \\
\text { VRS }\end{array}$ \\
\hline B01 & 3956.796 & 1894.426 & 9001.004 & 8701.497 & 1.000 \\
\hline B02 & 481.239 & 319.976 & 974.854 & 597.726 & 0.677 \\
\hline B03 & 305.200 & 138.600 & 479.800 & 252.200 & 0.640 \\
\hline B04 & 4710.680 & 3996.259 & 12920.337 & 6060.768 & 0.893 \\
\hline B05 & 1.018 & 1.282 & 3.054 & 0.377 & 1.000 \\
\hline B06 & 954.437 & 1208.703 & 1991.004 & 7278.097 & 1.000 \\
\hline B07 & 3.965 & 5.082 & 13.359 & 3.003 & 0.829 \\
\hline B08 & 14.630 & 16.863 & 44.659 & 14.938 & 0.738 \\
\hline B09 & 11.771 & 6.579 & 22.952 & 15.134 & 0.727 \\
\hline B10 & 364.920 & 244.750 & 923.510 & 1942.935 & 1.000 \\
\hline B11 & 4897.442 & 2787.181 & 11294.607 & 9363.232 & 0.939 \\
\hline B12 & 14.665 & 8.973 & 28.124 & 10.971 & 0.670 \\
\hline B13 & 6.077 & 14.249 & 26.994 & 10.207 & 0.970 \\
\hline B14 & 397.627 & 371.535 & 894.845 & 1902.878 & 0.813 \\
\hline B15 & 661.120 & 830.166 & 2325.128 & 1748.531 & 0.953 \\
\hline B16 & 12.125 & 7.346 & 33.573 & 19.530 & 0.960 \\
\hline B17 & 1222.026 & 1049.479 & 2959.509 & 2651.546 & 0.785 \\
\hline B18 & 931.172 & 838.346 & 2460.798 & 2765.485 & 0.866 \\
\hline B19 & 4070.351 & 2845.498 & 8377.368 & 7726.906 & 0.770 \\
\hline B20 & 3721.233 & 858.463 & 6953.701 & 2779.716 & 1.000 \\
\hline B21 & 16.137 & 7.080 & 40.771 & 22.126 & 1.000 \\
\hline B22 & 150.706 & 132.504 & 538.754 & 129.956 & 1.000 \\
\hline B23 & 3857.940 & 2894.374 & 7439.526 & 10239.087 & 0.910 \\
\hline B24 & 7994.808 & 2286.908 & 14156.194 & 11261.820 & 1.000 \\
\hline B25 & 9.689 & 6.975 & 22.432 & 6.032 & 0.756 \\
\hline B26 & 3292.736 & 1953.592 & 7041.164 & 3323.973 & 0.826 \\
\hline B27 & 402.772 & 321.189 & 906.237 & 775.778 & 0.678 \\
\hline B28 & 32.835 & 21.536 & 97.679 & 26.551 & 0.980 \\
\hline B29 & 6.737 & 7.854 & 18.402 & 4.504 & 0.690 \\
\hline B30 & 531.395 & 922.040 & 1672.093 & 1185.165 & 0.815 \\
\hline B31 & 152.510 & 190.361 & 685.374 & 769.898 & 1.000 \\
\hline B32 & 1.925 & 4.581 & 9.163 & 5.274 & 1.000 \\
\hline B33 & 4.889 & 6.737 & 17.402 & 5.082 & 0.840 \\
\hline B34 & 3233.619 & 2527.414 & 7959.733 & 4684.616 & 0.840 \\
\hline B35 & 5169.710 & 5405.975 & 15189.609 & 9830.137 & 0.871 \\
\hline B36 & 6802.566 & 5608.863 & 19958.043 & 15716.893 & 1.000 \\
\hline B37 & 3111.952 & 2126.013 & 6895.572 & 4869.316 & 0.811 \\
\hline B38 & 3600.983 & 1319.711 & 6547.924 & 5116.082 & 0.876 \\
\hline B39 & 7781.754 & 8486.425 & 27514.033 & 14335.679 & 1.000 \\
\hline B40 & 4488.666 & 4531.419 & 12157.913 & 12380.677 & 1.000 \\
\hline B41 & 3188.736 & 1106.154 & 5727.009 & 6194.460 & 1.000 \\
\hline B42 & 650.830 & 307.959 & 1265.646 & 441.359 & 0.780 \\
\hline
\end{tabular}

\section{Appendix B. Data for ten distributers in supply chain and efficiency scores}

\begin{tabular}{lllll}
\hline DMUs & $\begin{array}{l}\text { Staff } \\
\text { cost }\left(X_{j}\right)\end{array}$ & $\begin{array}{l}\text { Services } \\
\left(Y_{1 j}\right)\end{array}$ & $\begin{array}{l}\text { On-time } \\
\text { delivery }\left(Y_{2 j}\right)\end{array}$ & $\begin{array}{l}\text { VRS } \\
\text { efficiency } \\
\text { scores }\end{array}$ \\
\hline Behnoush & 29 & 170 & 220 & 0.991 \\
Abali & 32 & 189 & 138 & 0.891 \\
Kafir & 28 & 172 & 128 & 0.976 \\
Zam Zam & 35 & 193 & 149 & 0.823 \\
Khazar & 32 & 219 & 140 & 1.000 \\
Damdaran & 35 & 189 & 180 & 0.815 \\
Sara & 29 & 190 & 177 & 0.986 \\
Ramak & 26 & 153 & 209 & 1.000 \\
Pegah & 37 & 189 & 210 & 0.771 \\
Varna & 30 & 210 & 225 & 1.000 \\
\hline
\end{tabular}

\section{References}

Ahuja, R. K., \& Orlin, J. B. (2001). Inverse Optimization. Operations Research, 49(5), 771-783.

Amarchinta, H. K., Grandhi, R. V., Clauer, A. H., Langer, K., \& Stargel, D. S. (2010). Simulation of residual stress induced by a laser pending process through inverse optimization of material models. Journal of Materials Processing Technology, 210(14), 1997-2006.

Amin, G. R., \& Al-Muharrami, S. (2016). A new inverse data envelopment analysis model for mergers with negative data. IMA Journal of Management Mathematics. http://dx.doi.org/10.1093/imaman/dpw016. in press.

Amin, G. R., \& Emrouznejad, A. (2007a). Inverse forecasting: A new approach for predictive modeling. Computers E Industrial Engineering, 53(3), 491-498.

Amin, G. R., \& Emrouznejad, A. (2007b). Inverse linear programming in DEA. International Journal of Operations Research, 4(2), 105-109.

Banker, R. D., Charnes, A., \& Cooper, W. W. (1984). Some models for estimating technical and scale inefficiencies in data envelopment analysis. Management Science, 30(9), 1078-1092.

Charnes, A., Cooper, W. W., \& Rhodes, E. (1978). Measuring the efficiency of decision making units. European Journal of Operational Research, 2(6), 429-444.

Chow, J. Y. J., \& Recker, W. W. (2012). Inverse optimization with endogenous arrival time constraints to calibrate the household activity pattern problem. Transportation Research Part B: Methodological, 46(3), 463-479.

Emrouznejad, A., \& De Witte, K. (2010). COOPER-framework: A unified process for non-parametric projects. European Journal of Operational Research, 207(3), 1573-1586.

Emrouznejad, A., Parker, B. R., \& Tavares, G. (2008). Evaluation of research in efficiency and productivity: A survey and analysis of the first 30 years of scholarly literature in DEA. Socio-Economic Planning Sciences, 42(3), 151-157.

Gattoufi, S., Amin, G. R., \& Emrouznejad, A. (2014). A new inverse DEA method for merging banks. IMA Journal of Management Mathematics, 25(1), 73-87.

Gattoufi, S., Oral, M., Kumar, A., \& Reisman, A. (2004). Content analysis of data envelopment analysis literature and its comparison with that of other OR/MS fields. Journal of the Operational Research Society, 55, 911-935.

Ghiyasi, M. (2015). On inverse DEA model: The case of variable returns to scale. Computers \&' Industrial Engineering, 87, 407-409.

Huang, S., \& Liu, Z. (1999). On the inverse problem of linear programming and its application to minimum weight perfect k-matching. European Journal of Operational Research, 112(2), 421-426.

Jiang, Y., Xiao, X., Zhang, L., \& Zhang, J. (2011). A perturbation approach for a type of inverse linear programming problems. International Journal of Computer Mathematics, 88(3), 508-516. 
Lertworasirikul, S., Charnsethikul, P., \& Fang, S. C. (2011). Inverse data envelopment analysis model to preserve relative efficiency values: The case of variable returns to scale. Computers $\mathcal{E}$ Industrial Engineering, 61, 1017-1023.

Liu, Y., \& Li, J. (2009). Modelling and analysis of split and merge production systems with Bernoulli reliability machines. International Journal of Production Research, 47(16), 4373-4397.

Liu, J. S., Lu, L. Y. Y., Lu, W. M., \& Lin, B. J. Y. (2013). Data envelopment analysis $1978-$ 2010: A citation-based literature survey. Omega, 41, 3-15.

Mirhedayatian, S. M., Azadi, M., \& Farzipoor Saen, R. (2014). A novel network data envelopment analysis model for evaluating green supply chain management. International Journal of Production Economics, 147, 544-554.

Pibernik, R., Zhang, Y., Kerschbaum, F., \& Schröpfer, A. (2011). Secure collaborative supply chain planning and inverse optimization-The JELS model. European Journal of Operational Research, 208(1), 75-85.

Roch, J. R., Canelas, A, \& Herskovits, J. (2012). Shape optimization for inverse electromagnetic casting problems. Inverse Problems in Science and Engineering, 20(7), 951-972.
Ruiz, C., Conejo, A. J., \& Bertsimas, D. J. (2013). Revealing rival marginal offer prices via inverse optimization. IEEE Transactions on Power Systems, 28(3), 3056-3064.

Terekhov, A. V., \& Zatsiorsky, V. M. (2011). Analytical and numerical analysis of inverse optimization problems: Conditions of uniqueness and computational methods. Biological Cybernetics, 104(1-2), 75-93.

Wang, M., Xu, F., \& Wang, G. (2014). Sparse portfolio rebalancing model based on inverse optimization. Optimization Methods and Software, 29(2), 297-309.

Wei, Q., Zhang, J., \& Zhang, X. (2000). An inverse DEA model for inputs/outputs estimate. European Journal of Operational Research, 121(1), 151-163.

Yan, H., Wei, Q., \& Hao, G. (2002). DEA models for resource reallocation and production input/output estimation. European Journal of Operational Research, 136(1), 19-31.

Zhang, J., \& Liu, Z. (1996). Calculating some inverse linear programming problems. Journal of Computational and Applied Mathematics, 72(2), 261-273.

Zhang, J., \& Xu, C. (2010). Inverse optimization for linearly constrained convex separable programming problems. European Journal of Operational Research, 200 (3), 671-679. 